\title{
Camostat in COVID-19
}

\author{
Chinmoy K Bose* and Mohini Basu \\ Department of Health and Family, India
}

*Corresponding author: Chinmoy K Bose, Member, Subject Expert Committee, The Central Drugs Standard Control

Organisation (CDSCO), Directorate General of Health Services, Ministry of Health \& Family Welfare, India

\begin{tabular}{|c|c|}
\hline ARTICLE INFO & ABSTRACT \\
\hline Received: 㫪 May 27, 2020 & itation: Chinmoy K Bose, Mohini Basu. Camostat in COVID-19. Biomed J Sci \& Tech \\
\hline Published: 幽 June 03, 2020 & Res 28(1)-2020. BJSTR. MS.ID.004596. \\
\hline
\end{tabular}

\section{Mini Review}

Covid-19 has rapidly become greatest human tragedy of all time. Its huge dimension and speed world over has caught everybody unaware. After a short pause scientific community has risen strongly to the cause of finding remedy for this menace which started in the end of 2019 in Huanan wet market of Wuhan, China. While there are a number of compounds [1] attracting interest for trial in COVID-19 of some drugs with minimal proof are prescribed considering emergent situation. Recent blanket permission of use of hydroxychloroquine by FDA is a case in point. One such compound is camostat which is approved for other indication and which has a very interesting mechanism of action. It has very long and interesting history and recently gained interest as an alternative treatment for covid-19.

\section{FOY-305}

In 1977 p-Carbethoxyphenylepisol-guanidinocaproate and $\mathrm{p}$-( $\mathrm{p}$ '-guanidinobenzoyloxy)-phenyl derivatives and their benzoyl glycolate and benzilcarbonyloxyglycolate were found to be the most effective inhibitors of trypsin, plasmin, plasma kallikrien and thrombin [2]. Ohkoshi et al. [3,4] could show one such compound, [N,N-dimethylcarbamoylmethyl 4-(4-guanidinobenzoyloxy)phenylacetate] methane sulfate could inhibit growth of 3-methylcholanthrene-induced mouse skin tumor as protease inhibitor. This compound which was known as FOY-305 or camostate and could cure severe acute pancreatitis [5] also. Later it came to be known as camostat. It is a serine protease inhibitor. Serine protease enzymes have a variety of functions in the body, and so camostat has a diverse range of uses. Camostat is approved in Japan for the treatment of chronic pancreatitis and postoperative reflux esophagitis. The manufacturer is Ono Pharmaceutical. The drug is used in the treatment of some forms of cancer.

\section{Anti viral Property}

In a 2007 review, Hsieh et al. [6] described it as anti-influenza drug target which they thought was working by inhibiting viral hemagglutinin. Zhou et al [7] (Simmon's group) in 2015 tried to find if cysteine or serine proteases promote viral spread in the host. They compared the antiviral activity of an optimized $31 \mathrm{~K} 11777$ ((2S)$\mathrm{N}$-[(1E,3S)-1-(benzenesulfonyl)-5-phenylpent-1-en-3-yl]-2-\{[(E)4-methylpiperazine-1 carbonyl]amino\}-3-phenylpropanamide)derivative with that of camostat, an inhibitor of transmembrane protease, serine 2 (TMPRSS2) and related serine proteases. In pathogenic animal model of SARS-CoV infection, they demonstrated that viral spread and pathogenesis of SARS-CoV is driven by serine rather than cysteine proteases and can be effectively prevented by camostat. Naturally in early days of covid-19 pandemic a systematic review by Morse et al. [8] has mentioned this property of camostat by referring above work of Simmon's group.

In a seminal work, Hoffman et al. [9] did elaborate preclinical experiment with SARS-CoV-2 (Covid-19 or 2019-nCoV) in Germany. They transfected 293T human cell line by Covid-19 spike protein, SARS-2-S and compared with SARS spike protein, SARS-S and vesicular stomatitis virus (VSV) particles bearing SARS-2- S. S2 subunit of the $S$ protein was also observed in cells and, more prominently, in vesicular stomatitis virus (VSV) particles bearing SARS-2-S. In contrast, an S2 signal was largely absent in cells and particles expressing SARS-S suggesting efficient proteolytic processing of SARS-2-S in human cells. They also saw that most amino acid residues essential for ACE2 binding by SARS-S were conserved in SARS-2-S. Their study along with previous works highlight TMPRSS2 as a host cell factor that is critical for spread of several clinically relevant viruses, including influenza A viruses 
and corona virus covid-19. In contrast, TMPRSS2 is dispensable for development and homeostasis [10] and thus constitutes an attractive drug target. In this context, it is noteworthy that the serine protease inhibitor camostat mesylate, which blocks TMPRSS2 activity $[7,11]$ has been approved in Japan for human use, but for unrelated indication. This compound or related ones with potentially increased antiviral activity [12] could thus be considered for off- label treatment of SARS-CoV-2-infected patients.

\section{Current Clinical Trials}

After this preclinical experiment there are altogether four clinical trials on camostat till date. Among them two have not yet started recruiting. In Yale University Professor Joseph Vinetz will use it on 114 covid-19 patients in outdoor (OPD). This is a randomized placebo controlled trial expected to be over by the end of May (NCT04353284). Other phase II trial not yet recruiting is from Heinrich Heine University, Dusseldorf entitled Combination therapy with camostatmesilate + hydroxychloroquine for COVID-19 (CLOCC) (NCT04338906). Recruitment to be over by June and completion of study by December. This is a phase II trial. Other two 65 are active trials recruiting patients:

a. First one is Impact of Camostat Mesilate on COVID-19 Infection (CamoC0-19). The trial is placebo control, will recruit 580 cases in phase II A trial. Is this is in University of Aarhus, Denmark 68 (NCT04321096).

b. Second trial is open label study to compare efficacy, safety and tolerability of hydroxychloroquine combined with azithromycin compared to hydroxychloroquine combined with camostatmesylate and to "no treatment" in SARS CoV 2 Virus in Sheba Medical Center, Ramat Gan, Israel (NCT04355052).

\section{Conclusion}

The development of camostat as trypsin inhibitor to serine protease inhibitor working as antineoplastic, in chronic pancreatitis then in hepatic fibrosis has remained a fascinating journey in drug development adventure and seemed worth pursuing. We're hopeful that this drug will be useful in covid-19.

ISSN: 2574-1241

DOI: $10.26717 /$ BJSTR.2020.28.004596

Chinmoy K Bose. Biomed J Sci \& Tech Res

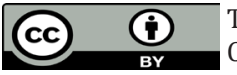

This work is licensed under Creative Commons Attribution 4.0 License

Submission Link: https://biomedres.us/submit-manuscript.php

\section{References}

1. Guangdi L, De Clercq E (2020) Therapeutic options for the 2019 novel coronavirus (2019-nCoV) Nat Rev Drug Discov 19(3): 149-150.

2. Tamura Y, Hirado M, Okamura K, Minato Y, Fujii S (1977) Synthetic inhibitors of trypsin, plasmin, kallikrein, thrombin, C1r-, and C1 esterase. Biochim Biophys Acta 484(2): 417-422.

3. Ohkoshi M (1981) Inhibition of growth of 3-methylcholanthrene-induced mouse skin tumor by protease inhibitor [N,N-dimethylcarbamoylmethyl 4-(4-guanidinobenzoyloxy)-phenylacetate] methanesulfate. Gan 72(6): 959-964.

4. Ohkoshi M, Fujii S (1983) Effect of the synthetic protease inhibitor [N,Ndimethylcarbamoyl-methyl 4- (4-guanidinobenzoyloxy)-phenylacetate] methanesulfate on carcinogenesis by 3-methylcholanthrene in mouse skin. J. Natl. Cancer Inst 71(5): 1053-1057.

5. Lankisch PG, Pohl U, Göke B, (1989) Effect of FOY-305 (camostate) on severe acute pancreatitis in two experimental animal models. Gastroenterology 97(6):1600.

6. Hsieh HP, Hsu JT (2007) Strategies of development of antiviral agents directed against influenza virus replication. Curr Pharm Des 13(34):3531-3542.

7. Zhou Y, Vedantham P, Lu K, Juliet Agudelo, Ricardo Carrion, et al. (2015) Protease inhibitors targeting coronavirus and filovirus entry. Antiviral Res 116:76-84

8. Morse JS, Lalonde T, Xu S, Liu WR (2020) Learning from the Past: Possible Urgent Prevention and Treatment Options for Severe Acute Respiratory Infections Caused by 2019-nCoV. Chembiochem 21(5):730-738.

9. Hoffmann M, Kleine-Weber H, Schroeder S, Nadine K, Tanja H, et al. (2020) SARS-CoV-2 Cell Entry Depends on ACE2 and TMPRSS2 and Is Blocked by a Clinically Proven Protease Inhibitor. Cell 181(2): 271-280.

10. Kawase M, Shirato K, Van Der Hoek L, Taguchi F, Matsuyama S (2012) Simultaneous treatment of human bronchial epithelial cells with serine and cysteine protease inhibitors prevents severe acute respiratory syndrome coronavirus entry. J. Virol 86(12): 6537-6545.

11. Kim TS, Heinlein C, Hackman RC, Nelson PS (2006) Phenotypic 139 analysis of mice lacking the Tmprss2-encoded protease. Mol. Cell. Biol 26(3): 965-975.

12. Yamamoto M, Matsuyama S, Li X, Takeda M, Kawaguchi Y, et al. (2016) Identification of Nafamostat as a Potent Inhibitor of Middle East Respiratory Syndrome Coronavirus S Protein-Mediated Membrane Fusion Using the Split-144 Protein-Based Cell-Cell Fusion Assay. Antimicrob. Agents Chemother 60(11): 6532-6539.

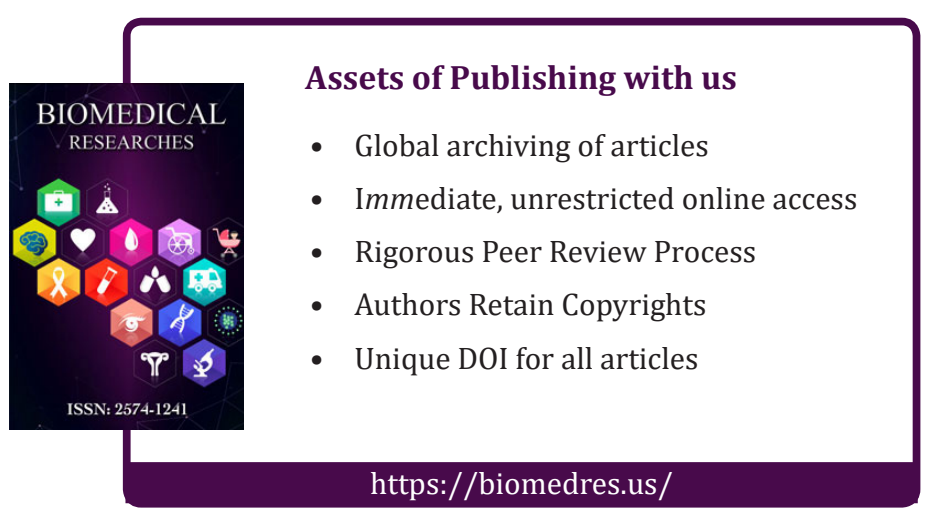

